\title{
Developing Digital Game Based on the Conception of Insects (DGBI) to Test Elementary Student's Insect Conceptions
}

\author{
Chow-Chin Lu' ${ }^{1}$, Shu-Li Jeng ${ }^{2}$ \\ ${ }^{1}$ Department of Science Education, National Taipei University of Education, Taipei \\ ${ }^{2}$ New Taipei City Jongjen Elementary School \\ Email: luchowch@tea.ntue.edu.tw
}

Received 2012

\begin{abstract}
The purpose of this study is to promote elementary school student's conception and interest of insect. In this study, we device a digital game, which possessed scientific and fun, base on the conception of insects (DGBI), then can use it to test elementary school student's conception about insect. The DGBI materials creating pattern use as the ADDIE model. First step is to analyze the DGBI materials. We analyze student's alternative conceptions of insect and what the teaching staff needs to teach in the section of insect, and then we develop three teaching units, namely the - Bugs Adventure $\|$, - Legs and Wings "and" Mouthparts and feeding habits $\|$. Second, design the DGBI. Making DGBI has a clear teaching aim, multi-learning strategy like conception puzzle, computer simulation and conception mapping etc, an artistic and convenient operating media interface and a learning content that is easy to understand by the words and video in the DGBI materials. Third, develop the DGBI. Developing DGBI includes making animation component and composing animation component, these animation components makes $94.4 \%$ of students prefer to use DGBI materials to learn the conceptions of insect, especially the constructional detail magnify function and interactive game design in the teaching materials increase the student's learning interest. Forth, implement DGBI. We invite Two national college professors and four senior science teachers to use DGBI, and then we interview them to collect the testing amendments, and corrected it.Fifth, evaluate DGBI. We use quasi-experiment design and questionnaire survey to evaluate DGBI. In the quasi-experiment design, we select 111 students for four classes in an elementary school in New Taipei City and ask them to use DGBI, and then we tested them by the - Insects Conceptions test II. We found that after using the DGBI materials, the student's post-test scores (13.64) is higher than the pre-test scores (7.55), and there are significant differences $(\mathrm{t}=16.47, \mathrm{p}=.00)$ and helps the student to establish the correct concept of insect.. In the questionnaire survey, we ask 6 elementary school teachers to write down the -digital materials quality certification evaluation form $\|$ after using DGBI. The teachers think that DGBI has an organizational integrity of the insect teaching material. When using DGBI, they can teach the insect unit as a game, and student can learn the insect unit on student's own initiative, which allows students to study the conceptions of insect step-by-step.
\end{abstract}

Keywords: Digital Game Based on Insects (DGBI); ADDIE; Insects Conceptions test; Digital Materials Quality Certification Evaluation Form

\section{Introduction}

\section{Rationale and Importance of This Study}

Insects has the most widely distributed and the largest number of animals on Earth, even thought students has to learn insects curriculum in schools, but after learning, students are still unfamiliar with insects, and has lots of alternative concepts(Zhuang, 2002). Bell \& Baker (1982) study elementary school student's insect concept and found that $56.9 \%$ of students do not know that insects have two pairs of wings. Huang (2003) use two-stage diagnostic as research tools to study the insect's alternative conceptions of elementary school students, and found that $67.5 \%$ of fifth grade and sixth grade students thinks that insects feet scattered at different body parts of insects. Before student start learning insect curriculum in school, they learn the insect concept from book pictures, picture books or TV media (Lu, Chen, \& Chen, 2011), but in order to attract children's interest, most of the books and media often try to make the insect appearance and habits to be anthropomorphic, which pass on the wrong message to children and will let them prone to have the wrong conceptions. If we don't guide them to have the right conceptions, it might effects their future learning in insects (Lu \& Chen, 2008; Lu et al., 2011; Marriott, 2002)

The most effective strategy to change the wrong concept is bring the students to go out in field and observe the insects, but some of the insects is hard to find and observe, which made the teaching curriculum really difficult (Chen, 2004). Most of the elementary science teachers in Taiwan, did not have a formal incest training in their college education, therefore some of the teachers has alternative conceptions of insect's appearance features, insect's structure, insect's life history and insect's habits themselves, which might pass the wrong conceptions to student when they were teaching ( $\mathrm{Lu}, \&$ Chen, 2011). Some of the teacher thinks that teaching the insect unit in science is really hard, owing to their limit of insect conceptions and have restricted by pictures and words in the test book, and cause the domestic insects teaching plight (Chen, 2004). Students are active constructors to their knowledge, if science teacher can 
teach the correct insect conception with the right materials and bring out students interested, it will make the learning more effective. In this study, we try to design an interest scientific digital teaching materials to help elementary school student learn the correct insect conception. The insect conception teaching materials use conceptual change teaching strategies to design the it, and wish to build up a materials that can help the students to create right insect conceptions.

\section{Research Objective}

This study adopted the systematic design of instruction teaching model (ADDIE) to design a digital game based on the conception of insects (DBGI) teaching material that can detect elementary school student's insect concept, which are interesting and has scientific insect concept in it. In this study we probe five questions: First, how do us analysis the DBGI teaching material base on student alternative conceptions. Second, what kind of DBGI teaching material designing can accomplish our goal? Third, how do we make the DBGI teaching material? Forth, how to implement the DBGI teaching material in teaching? Fifth, how do we evaluation the DBGI teaching material?

\section{Literature Review}

\section{Using ADDIE Model to Design Digital Teaching Materials}

Chuang \& Su (1999) use the questionnaire to survey elementary schools student's insect classification concepts and found that only $13.2 \%$ of students say the insect have six legs. Trowbridge \& Mintzes (1988) use animal picture cards to survey student's insect classification concepts and found children define insect as — small body type animals. II They think animals like centipede, diplopod, earthworm and spiders are insects. Shepardson (2002) survey fourth grade elementary school students and found $61.0 \%$ students think that insects have only one wind. And $80.0 \%$ of students believe that insects are herbivorous. Huang (2003) discover students know dragonflies have two pair of wings, but could not identify ladybug and stick insects also have two pair of wings. Chen (2003) survey student's aquatic insects concept by questionnaire and found only $62.2 \%$ of students can use the characteristic of -insect have six feet $\|$ to determine whether it is aquatic insects or not.

\section{Studies of Elementary Schools Student'S Insect Classification Concepts}

The ADDIE model is the generic process traditionally used by instructional designers and training developers. The five phases-Analysis, Design, Development, Implementation, and Evaluation-represent a dynamic, flexible guideline for building effective training and performance support tools (Molenda, 2003). In an abstraction teaching activities or teaching activities require drills and hard to obtain the teaching resources, the digital game-based teaching material, who has good playability and is instructive becomes a good teaching medium and effects student to actively participate in the class and have lots of fun (Squire, 2003). In this research, we try to use the ADDIE as model and develop a digital game-base teaching material to detect student's alternative conceptions of insect. We classify the game as a puzzle action game and manufacture it with the function to provide practice opportunities. The game not only can effect students visual sensory and stabilizing their cognitive feelings, but also can assess their self-restraint and the ability to use electronic media (Squire, 2003).

\section{Methodology}

\section{Research Design}

The DGBI teaching materials can divided into two phases: development phase and evaluation phase. In development phase, we design and develop the DGBI teaching materials base on ADDIE systematic design of instruction teaching mode shown in Figure 1. In the evaluation phase, we use questionnaire and quasi-experimental research method to evaluate the feasibility and the effectiveness of establishment children's correctly insects concept of DGBI teaching materials(Figure 1).

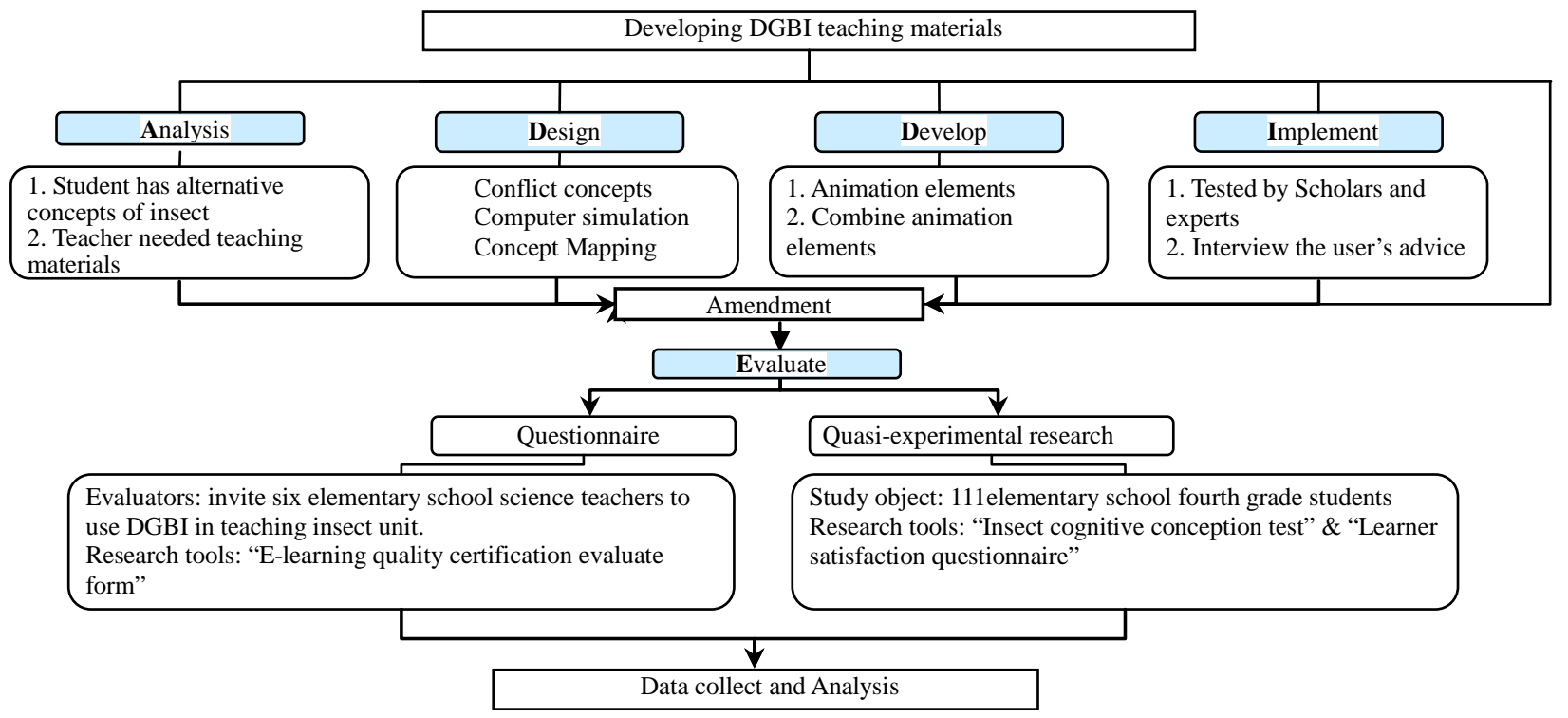

Figure 1.

Proposed research model of developing DBGI teaching materials. 


\section{Research Tools}

\section{E-learning Quality Certification Evaluate Form}

In this research, we use the -E-learning quality certification evaluate form II, which was develop by Sung, Chang, Lin, Lee, \& Chen, (2009). The form has four dimensions, including: content, navigation, instructional design and instructional media. The evaluators will give 0 to 8 point when evaluating the digital teaching design; the maximal score is 104 point. Certification grade - A \| means the teaching materials got 65 to 74 points in the test; if it got grade AA, it means certification grade is over 78 to 90 points; if the certification grade is over 91 point, it can be certificate as AAA grade.

\section{Learner Satisfaction Questionnaire}

In this study, we use - Learner satisfaction questionnaire \| design by Jeng (2012) to survey student's satisfaction when using DGBI in their learning. In the questionnaire, we investigate their preferences in textbook content and the advantages and disadvantages of DGBI teaching materials. Due to our research objects are fourth grade elementary students, we provide answer options for each question in our questionnaire, which students can finish the questionnaire by putting a check mark in the blank. If they want to express their thought, there is also another blank field in the questionnaire, which can let them express themselves to us.

\section{Insect Cognitive Conception Test}

In this study, we use "Learner satisfaction questionnaire" design by Jeng (2012) to survey student's satisfaction when using DGBI in their learning. In the questionnaire, we investigate their preferences in textbook content and the advantages and disadvantages of DGBI teaching materials. Due to our research objects are fourth grade elementary students, we provide answer options for each question in our questionnaire, which students can finish the questionnaire by putting a check mark in the blank. If they want to express their thought, there is also another blank field in the questionnaire, which can let them express themselves to us.

\section{Insect Cognitive Conception Test}

In the study, we also use the "Insect cognitive conception test” that was design by Jeng (2012). It has 21 questions in the test, includes seven questions that ask "Identify insects", seven questions that ask "book the position of insect's feet and wings" and seven questions ask about "insect's mouthparts and eating habits". The Cronbach's $\alpha$ of this test is .708 and show the test has reliability which was capable to use.

\section{Data Collection}

In our researcher, we collected both quantitative and qualitative data. E-learning quality certifications evaluate form, Learner satisfaction questionnaire and Insect cognitive conception test is our quantitative data. These data present the evaluation results of the DGBI teaching materials. It display with statistical average and shows the DGBI teaching materials is validity in improving student's insect conceptions.

The qualitative data includes DGBI user's interviewing record, evaluator's interview record and student's interviews. We use interpretative analysis to grasp the details suggestion of our users, evaluators and students after using DGBI teaching materials.

\section{Results}

\section{Analysis Phase of DGBI Teaching Materials}

Integrate information from literature, experiment teaching and teachers whom use DGBI in their teaching, they proposed that student's alternative conceptions to insect is students will use their intuition to determine if an animal is insect or not. When they have the right intuition to insect and judge the animals by using the numbers of their feet, they can easily decide if it's an insect or not. But if the students have the wrong intuition, students will get the alternative conceptions and considered lots of small animals are insects.

In the part of booking the insect's feet in the right position, we found that some student's insect conceptions did effected by modern media and bring out student's alternative conceptions. In order to attract the children's attraction, some media often anthropomorphic the insect and put a pair of their legs in the abdomen of the tagma which was the wrong conception.

The relationship of insect's mouthparts and eating habits is another part that student is confuse about. Due to students doesn't have the experience of rising or observing lots of insect. Some of the students even think insect's mouthparts has the same function as human's teeth.

\section{Designing Phase of DGBI Teaching Materials}

The designing of DGBI teaching materials is using teaching strategies as conflict the concept, computer simulation, and concept mapping strategy. We sort out the name of our unit, our teaching goals and teaching activities into a list, shown as Figure 2.

As we see in Figure 2, the designing concept of "Bugs Adventure” is according to understand the basic insect conceptions. "Legs and Wings" in accordance with the concept of identify the right position of insect's feet. The "Mouthparts and feeding habits" unit comes from the idea of recognize the mouthparts of insect and the relationship between mouthparts and their feeding habits.

1) Conflict concepts tactics: In the Legs and Wings puzzle game; we choose to use pictures that often show in cartoons, which their legs and wings were in the wrong position of the insect tagmata as dragonflies, butterflies and beetle. Then, we let students to put the puzzle of three pairs of legs and two pairs of wings in the right tagmata of the insect. In this activities, students has to finish the game by clicking insect's legs and wings from the computer surface and putting the puzzle in the correct position.

2) Computer simulation tactics: In insect curriculum, teachers' biggest challenge is that it is hard to let students to observe the insect by themselves. In order to solve teachers teaching problems, we use computer simulation tactics. It can show the insect's entity simulating 3D animation (360 degree rotation), zoom their portion features and emphasis our teaching focus to the students.

3) Mapping concept tactics: In DGBI, we utilize the concept of "filling the concept diagram in the blank" form Tsai (2008) and shows parts of expert's conception map to students. Then, we ask students to choose the concepts terms at the bottom of the surface and drag and drop it into the concepts space above as Figure 3.

\section{Development Phase of DGBI Teaching Materials}

The aim of DGBI teaching materials is to improve students' insect concept. So, the DGBI user interface needs to design for the children and the concept must be the ones that they were not 
familiar with. We design and process DGBI teaching materials based on the alternative conception data we had have collected in the analysis stage, and organized it into development phase diagram, shown as Figure 4.

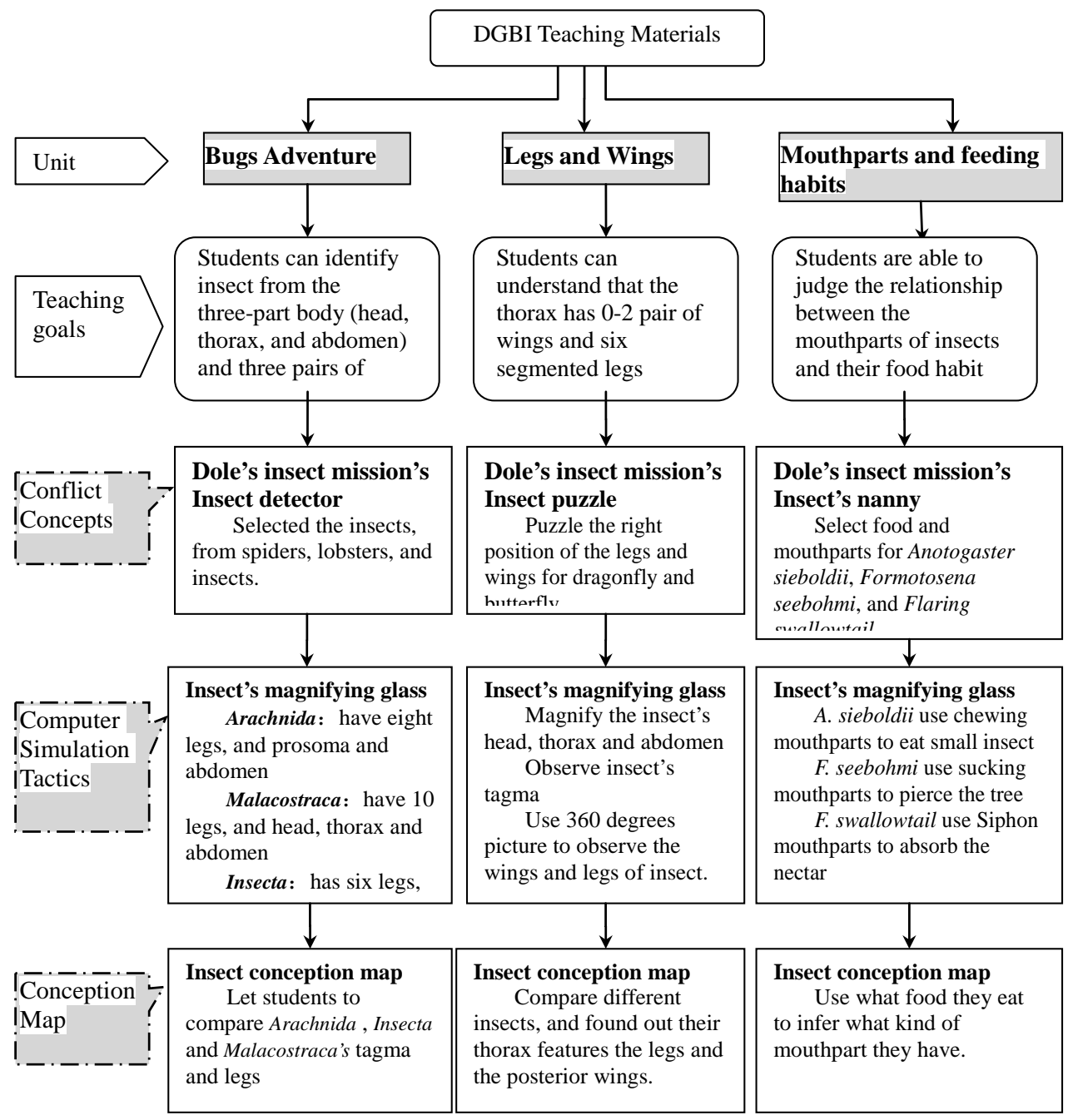

Figure 2.

Development phases of DGBI teaching materials.

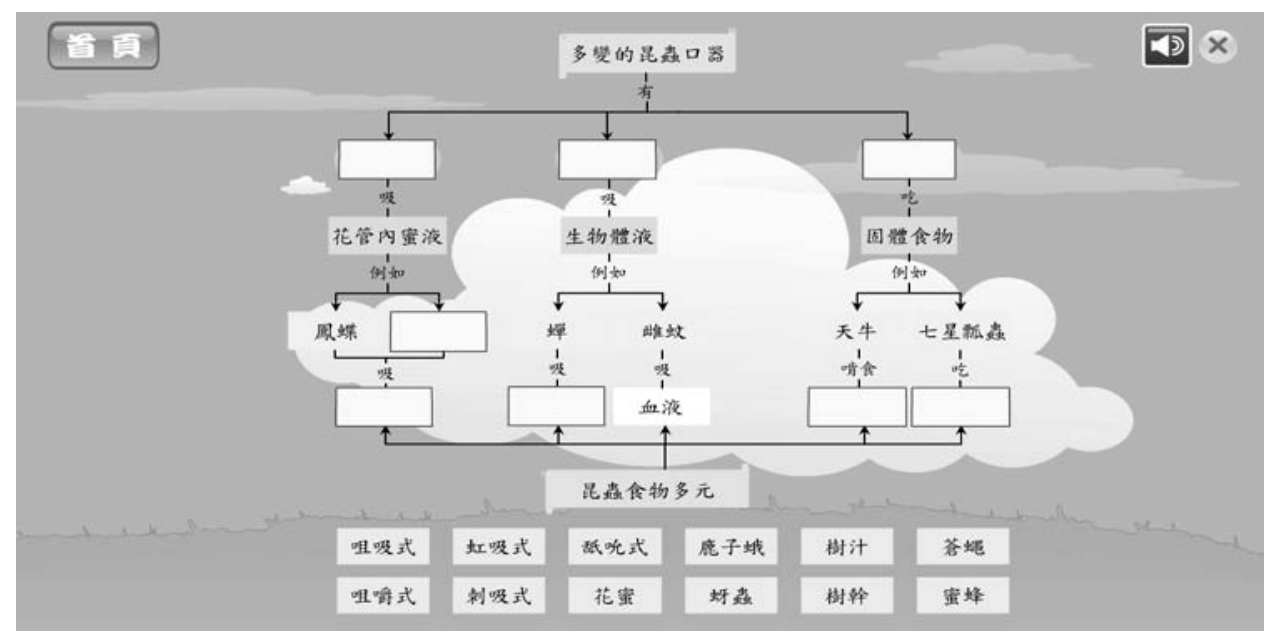

Figure 3.

Designing examples of conception map in DGBI teaching. 
Developing DGBI teaching materials, we use animation software: Adobe Flash CS4 Professional to make the teaching materials. In the teaching material, we collected the photos (most of them we shot it ourselves), music and picture from the internet resources. There are three buttons in the index page for children to choose, includes logout button ( $x$ ), start button, and game description. If the student mouse moves to the log out button, it will show a prompt "don't want to play anymore"; pressing the logout button, the system will log out DGBI immediately. In all the upper right corner of DGBI interface, will apparel this logout button to let learners to choose if they want to leave the teaching material or not (shown in Figure 5). When pressing start button and game description, it will show activities menu and the teaching materials help page.

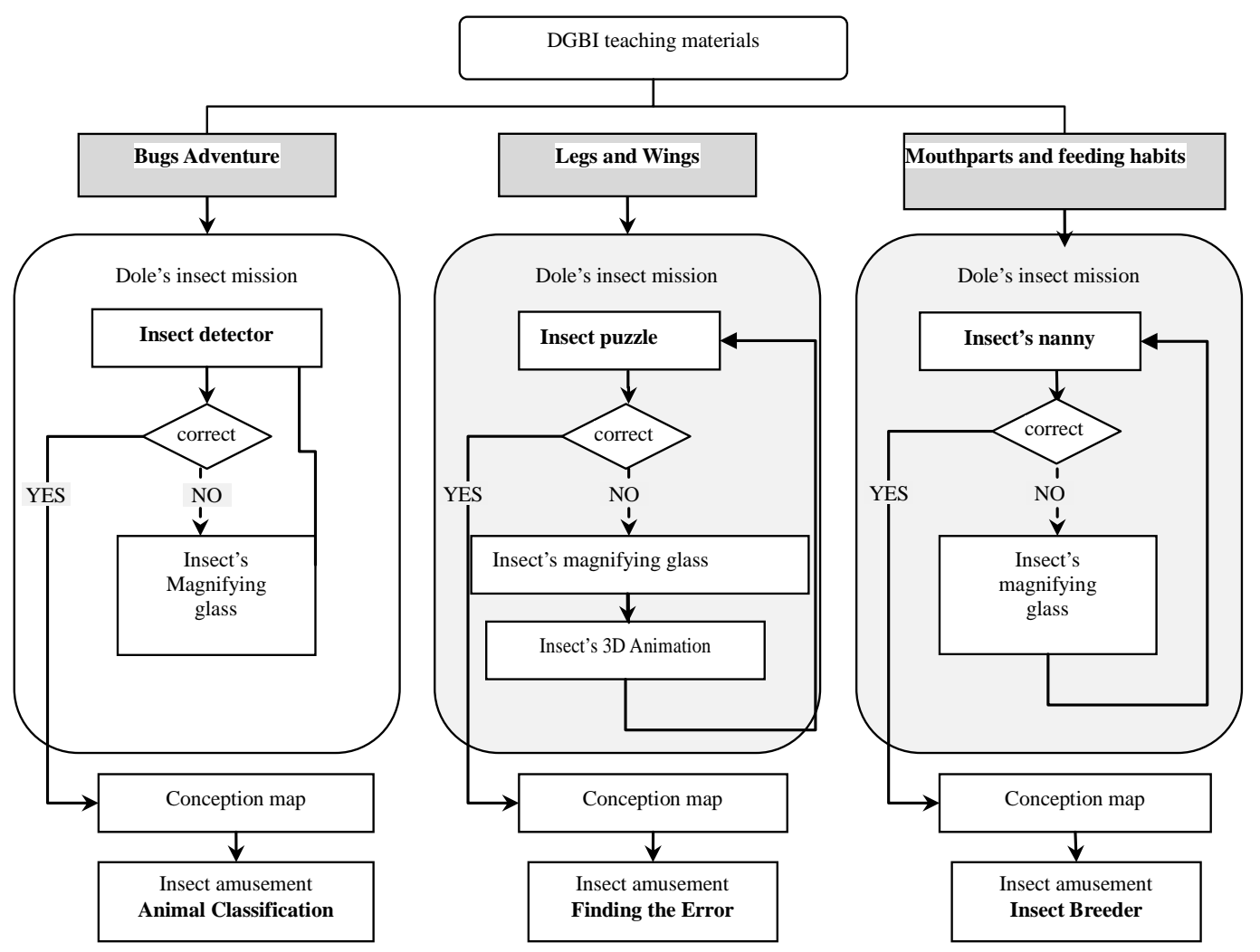

Figure 4.

Development phase of DGBI teaching materials diagram.

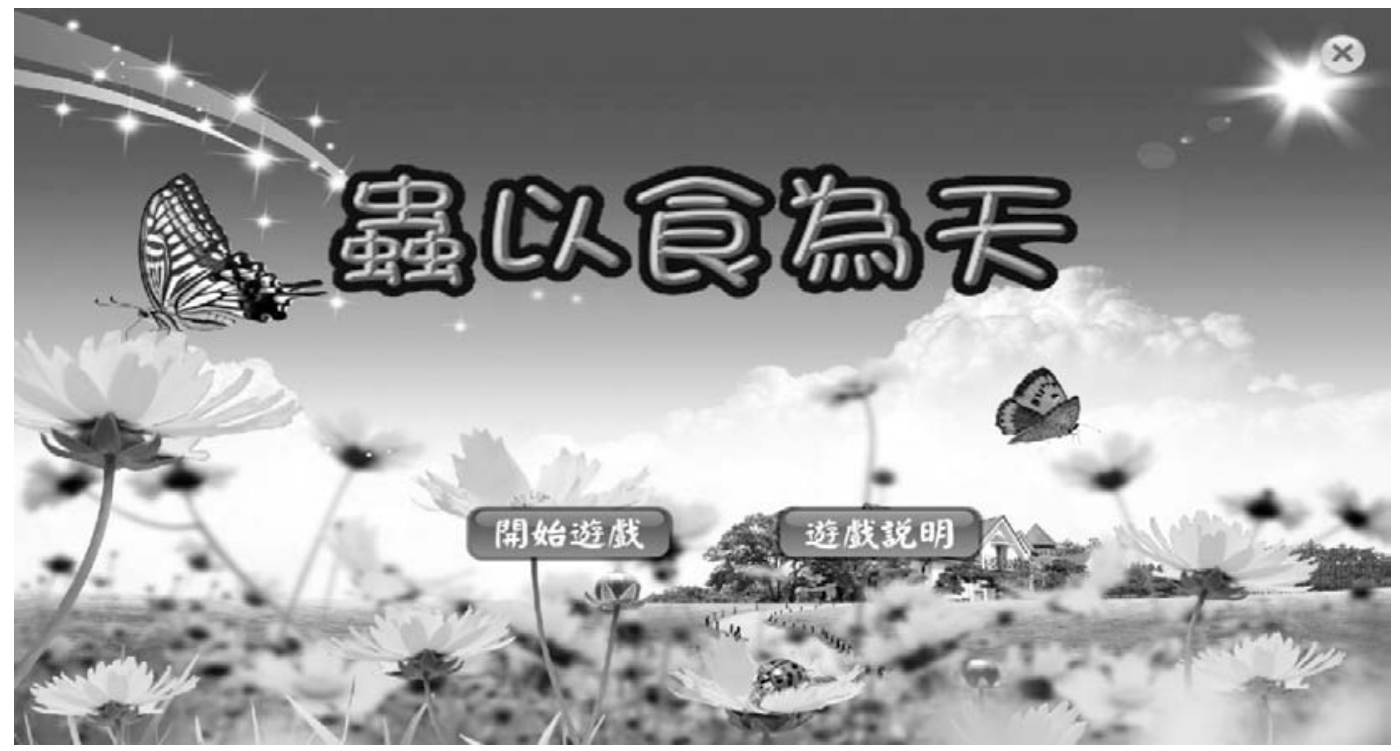

Figure 5.

DGBI teaching material's index page. 
In activities menu, there are six buttons for students to choose, includes three control button: homepage, sound control (四), logout button $\left({ }^{x}\right)$ and three activities options "Dole's insect mission (shown as Figure 6)" "Conception map", and "Insect amusement". The background music can enhance students learning, but it also can caused the interference of learning; therefore, learners might use the sound control buttons ( to control if they want to have the music or not. After pressing the mouse button, the button will turn to which means the learner turn off the music; pressing the button again, it will turn back to which means the music is on again.

DGBI teaching materials can give different learners different feedbacks. If learners has the wrong options, the DGBI will directed to the prompt page, and shows the appropriate prompt to let student's to think again about their answers. In the bottom right of the surface, students can press try again to finfish the learning mission. If the learner answers the right answer, then the DGBI will give them a positive feedback and affirm their options.

In the insect amusement activities: 1. Animal classification: Student can use the concept of number of animal foot and body parts (head, thorax and abdomen) to classify insect. In the game, learners need to use the mouse and move the animals from the left to the right to accomplish the game (shown as Figure 7). 2. Finding the Error: We applied the conception that insect's thorax features the legs and wings in the activity. In the game, the learners needs to point out wrong position of the legs and wings to accomplish the game (shown as Figure 8). 3. Insect Breeder: Students needs to use the mouthparts structure to determine

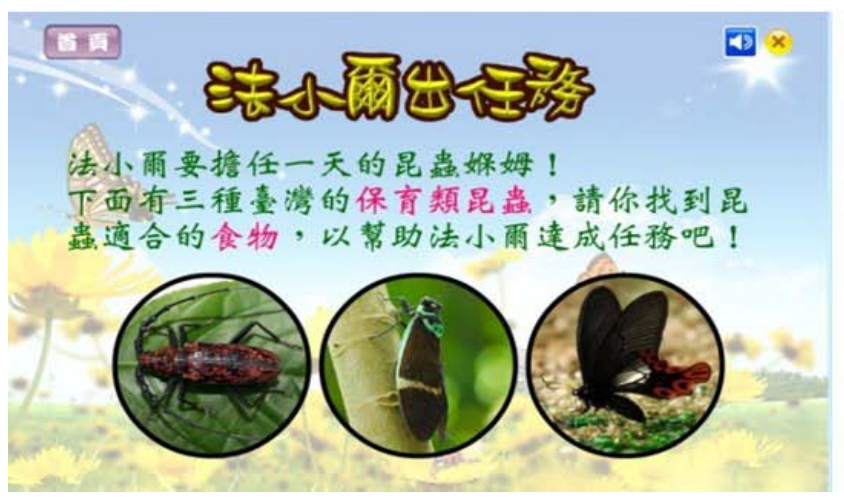

Figure 6.

The design of "Dole's insect mission".

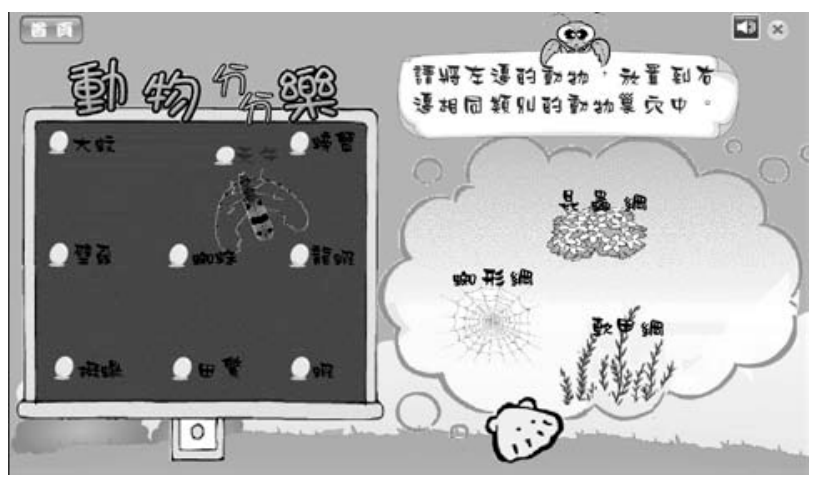

Figure 7.

The interface game pictures of insect amusement. what kind of food they eat, and give the food to the right inset. In the game, learner needs to use the keyboard to control the direction and bring the food to the right place (shown in Figure 9).

\section{Testing the DGBI Teaching Materials}

We invite two international professors (specialty in insects, P1-P2), three senior elementary school science teachers (T2-T4) and one elementary school computer teachers (T1) to test DGBI teaching materials and interview them for their suggestions, and use it as the reference when corrected DGBI. We sort out the interview results and the correction as Table $\mathbf{1 .}$

\section{Evaluation Phase of DGBI Teaching Materials}

\section{E-learning Quality Certification Evaluate Form}

After finishing the DGBI, we ask six evaluators to evaluate the designing results of DGBI, shown in Table 2. The evaluators give the DGBI teaching materials the highest certification level: AAA level.

Supplemented with evaluator interview result instruction:

- The Digital teaching materials have correct content and clear pictures; the content is interesting and fun, the scientific concepts is express correctly. The organizations of the teaching materials are completely and can gives students appropriate breadth and depth learning step-by-step; there are variety of ways to promote learning in DGBI, as conception map, game assessment, 360 degrees rotation of insects and answer providing etc. (DGA-T1, T4, T5, T6, 20120303).

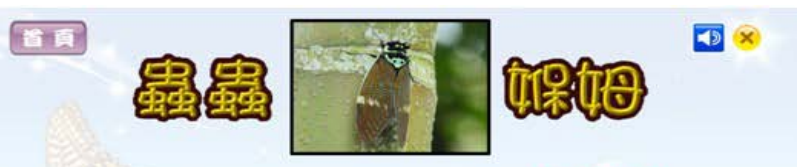

請禁法小爾找一找, 下面哪個束西是蟬的食物?

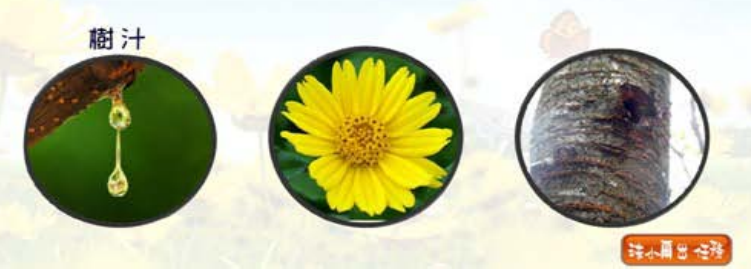

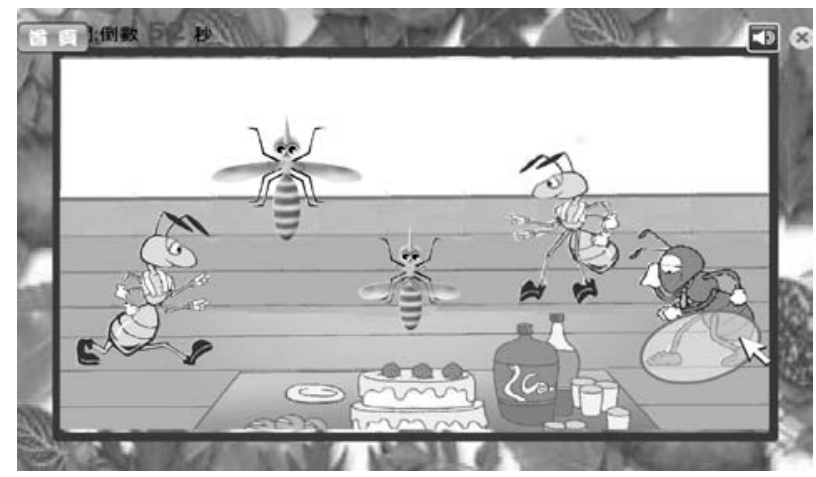

Figure 8.

The interface game pictures of finding the error. 


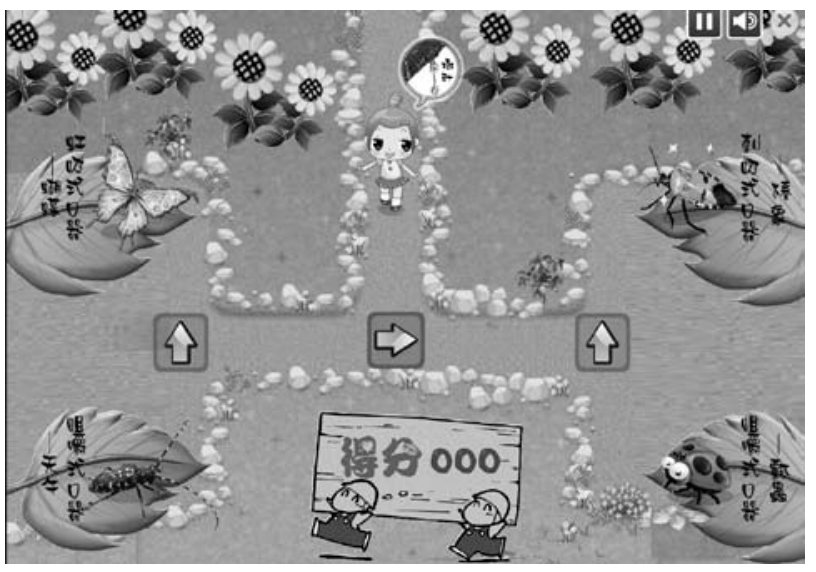

Figure 9.

The interface game pictures of insect breeder.
- DGBI has integrated framework, clearly divide each units; the content is vivid and lively and the terms is unique ingenuity; the concept map puzzle and game design is a way to practice and assesses students; in the concept map puzzling activity, the design of showing the answer can provide helps when their learning (DGA-T1, T2, T3, T4, 20120303).

- DGBI teaching materials don't have learning recording function, which can be reinforce; the content in DGBI lay particular stress on the words, if it can added some voice to lead students to read will obtain a better learning results (DGA-T2, T3, T5, 20120303).A-T2, T3, T5, 20120303).

\section{Insect Cognitive Conception Test}

In the insect cognitive conception test survey, we exclude the error questionnaire sheets and get 107 valid questionnaire sheets. The pre-test and post-test result of insect cognitive conception test is shown in Table 3.

Table 1.

Testing results and corrections of DGBI teaching materials.

\begin{tabular}{|c|c|c|c|}
\hline Dimension & Users suggestion & \multicolumn{2}{|l|}{ Corrections } \\
\hline $\begin{array}{l}1 . \\
\text { Teaching } \\
\text { Contents }\end{array}$ & $\begin{array}{l}\text { 1-1. DGBI can mention more insect type } \\
\text { (DGInv-P1,P2,20120202; } \\
\text { DGInv-T3,T4,20120224) } \\
\text { 1-2. Can put in some Hymenoptera insects } \\
\text { (DGInv-T1,P1, 20120211) } \\
1-3 . \quad \text { Scientific terms don't use “Somite" of } \\
\text { insect, can change to tagma of insect } \\
\text { (DGInv-T1,20120211) }\end{array}$ & \multicolumn{2}{|c|}{$\begin{array}{l}\text { 1-1-1 We have Coleoptera, Lepidoptera, Hymenoptera insects in the unit already, } \\
\text { but we also added Hemiptera and Homoptera two kinds of insect for examples in } \\
\text { the unit. } \\
\text { 1-1-2 Added beetle in the Legs and Wings unit, which can give more example to } \\
\text { student } \\
1-2-1 \text { Change the ladybug, cicada and dragonfly into bees, ladybug and cicada. } \\
\text { 1-3-1 Fix the word "Somite" to "Tagma", which can let the student have better } \\
\text { conceptions. }\end{array}$} \\
\hline $\begin{array}{l}2 . \\
\text { Learning } \\
\text { Direction }\end{array}$ & $\begin{array}{l}\text { 2-1. Conception map might make the underper- } \\
\text { formed the children to give up practicing } \\
\text { (DGInv-T2, T3, 20120202) } \\
\text { 2-2. Can emphasize the learning point again after } \\
\text { the game (DGInv-T1, 20120211) }\end{array}$ & \multicolumn{2}{|c|}{$\begin{array}{l}\text { 2-1-1 We added the key which can show the answer when they have difficult } \\
\text { learning. } \\
\text { 2-2-1 We added the learning point prompted function, to emphasize the learning } \\
\text { point again after the game was over. }\end{array}$} \\
\hline $\begin{array}{l}3 . \\
\text { Teaching } \\
\text { Design }\end{array}$ & $\begin{array}{l}\text { 3-1.DGBI learning feedback isn’t enough } \\
\text { (DGInv-P2, T1, 20120211) }\end{array}$ & \multicolumn{2}{|c|}{$\begin{array}{l}3-1-1 \text { We use the sound to strengthen the immediately feedback. } \\
3-1-2 \text { We added the timing function to increase the irritating of the game. }\end{array}$} \\
\hline $\begin{array}{l}4 . \\
\text { Teaching } \\
\text { Media }\end{array}$ & $\begin{array}{l}\text { 4-1. The color of the description text can be } \\
\text { affected by the background picture, and reduce the } \\
\text { comfort of reading (DGInv-T1, T2, T4, } \\
\text { 20120224). } \\
\text { 4-2.Can added some background music } \\
\text { (DGInv- T1, T4, 20120224). }\end{array}$ & \multicolumn{2}{|c|}{$\begin{array}{l}\text { 4-1-1 We change the texts' color into the color that is contrast from the picture. } \\
\text { 4-2-1 We choose Chinese children rhymes (Dragonfly and A beautiful butterfly) } \\
\text { as the background music, and added a background sound off button. }\end{array}$} \\
\hline \multicolumn{2}{|c|}{ Evaluation dimension } & Mean & Standard deviation \\
\hline \multicolumn{2}{|c|}{ 1. Teaching Contents (Content, total score 21) } & 19.6 & 1.08 \\
\hline \multicolumn{2}{|c|}{ 2. Learning Directions (Navigation, total score 19) } & 16.0 & 2.10 \\
\hline \multicolumn{2}{|c|}{ 3. Teaching Design (Instructional design, total score 43) } & 41.3 & 1.63 \\
\hline \multicolumn{2}{|c|}{ 4. Teaching Media (Instructional media, total score 21) } & 19.0 & 1.10 \\
\hline \multicolumn{2}{|c|}{ Total score (Total, total score 104) } & 95.9 & 4.37 \\
\hline
\end{tabular}

From Table 3, we can know that students discrepancy between pre-test and post-test results from insect cognitive conception test is 6.08; the total score of t-test is 16.47 , and the "Insect identification" get's $t=8.85$; the "Position of legs and wings" get's $t=14.96$; the "Mouthparts and feeding habits" get's $t=7.02(p=.00)$. This shows that students have significant progress on the total score and three conceptual category after using DGBI. Then, we analysis students final score and divided them into three groups, according to their "insect cognitive conception test”. $27.3 \%$ student in the top grouped as 
high score ranking group, and grouped the bottom 29 students (bottom 27.3\%) as low-score group. The other $45.4 \%$ of students became the Middle Score Group. The performance in the “insect cognitive conception test" sort out as Table 4.

We can see in table4 that the high score group, middle score group and lower score group t-test result is $t=7.13,10.96$, $13.53, p=.00$. This shows that three groups have significant progress in insect after using DGBI in learning. Especially the lower score group have the most obvious learning effects (Average rating discrepancy $=8.67$ ).

We can see in Table 4 that the high score group, middle score group and lower score group t-test result is $t=7.13,10.96$, $13.53, \mathrm{p}=.00$. This shows that three groups have significant progress in insect after using DGBI in learning. Especially the lower score group have the most obvious learning effects (Av- erage rating discrepancy $=8.67$ ).

\section{Learner Satisfaction Questionnaire Sheet}

In the questionnaire survey, we exclude 3 error questionnaire sheets and get 108 valid questionnaire sheets. The questionnaire sheet includes three multiple choice questions(Q1、Q2、Q3) and two multiple-choice questions(Q4、Q5). After statistics the data, we sort out all 5 questions and shown as figure 10, which was supplemented with qualitative described data.

In Figure 10a, we found out that $94.4 \%$ of students like to use computer to learn insect concept. The reason they like to learn by computer, $52.0 \%$ of students thinks it fun and interesting, $30.4 \%$ of students think that they help to understand the conception of insect more effective. The interviews are as follows:

Table 3.

Test performance of forth grade students' insects cognitive concept.

\begin{tabular}{|c|c|c|c|c|c|c|c|}
\hline \multirow{2}{*}{ Conceptual category } & \multicolumn{2}{|c|}{ Pre-test $(N=107)$} & \multicolumn{2}{|c|}{ Post-test $(N=107)$} & \multirow{2}{*}{$d$} & \multirow{2}{*}{$t$} & \multirow[b]{2}{*}{$p$} \\
\hline & $M$ & $S D$ & $M$ & $S D$ & & & \\
\hline Insect identification & 2.30 & 1.39 & 3.97 & 1.76 & 1.67 & 8.85 & $.00 * *$ \\
\hline Position of legs and wings & 2.38 & 1.31 & 5.66 & 1.82 & 3.28 & 14.96 & $.00 * *$ \\
\hline Mouthparts and feeding habits & 2.87 & 1.33 & 4.00 & 1.32 & 1.13 & 7.02 & $.00 * *$ \\
\hline Total score & 7.55 & 2.53 & 13.64 & 3.65 & 6.08 & 16.47 & $.00 * *$ \\
\hline
\end{tabular}

M: Mean; SD: Standard Deviation; D: Discrepancy between Pre-test and Post-test; ${ }^{* *} \mathrm{p}<.00$.

Table 4.

Different learning achievement performance of forth grade student's.

\begin{tabular}{|c|c|c|c|c|c|c|c|}
\hline \multirow{2}{*}{$\begin{array}{c}\text { Category of learning achieve- } \\
\text { ment }\end{array}$} & \multicolumn{2}{|c|}{ Pre-test } & \multicolumn{2}{|c|}{ Post-test } & \multirow{2}{*}{$d$} & \multirow{2}{*}{$t$} & \multirow{2}{*}{$p$} \\
\hline & $M$ & $S D$ & $M$ & $S$ & & & \\
\hline High Score Group $(N=29)$ & 10.65 & 1.59 & 14.86 & 3.61 & 4.21 & 7.13 & $.00 * *$ \\
\hline Middle Score Group $(N=49)$ & 7.45 & .94 & 13.12 & 3.67 & 5.67 & 10.96 & $.00 * *$ \\
\hline Low-Score Group $(N=29)$ & 4.62 & 1.18 & 13.28 & 3.48 & 8.67 & 13.53 & $.00 * *$ \\
\hline
\end{tabular}

M: Mean; SD: Standard Deviation; D: Discrepancy between Pre-test and Post-test; ${ }^{* *} \mathrm{p}<.00$.

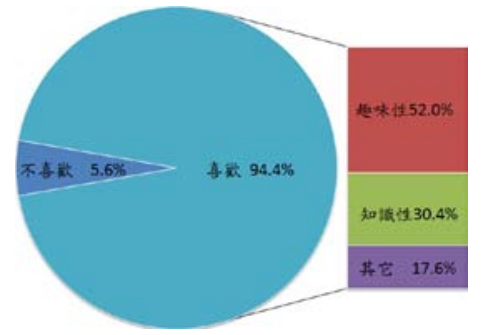

(a)

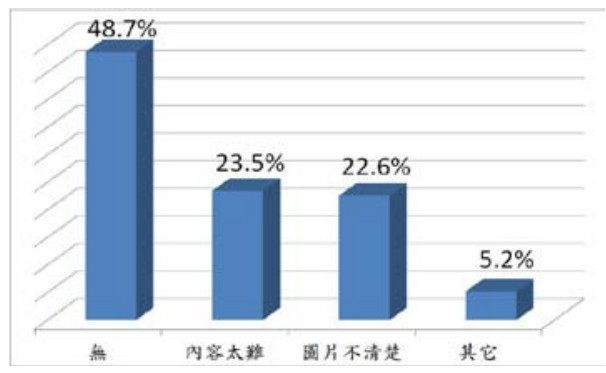

(d)

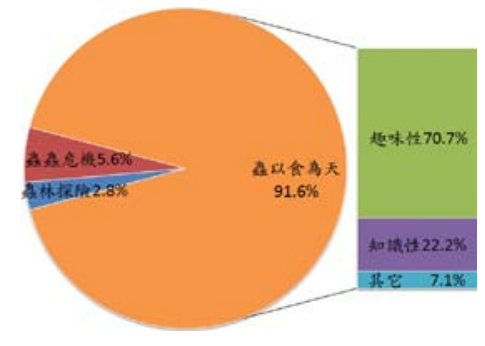

(b)

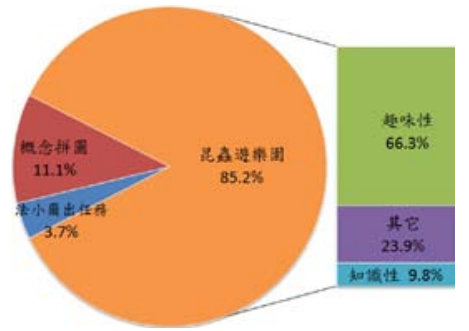

(c)

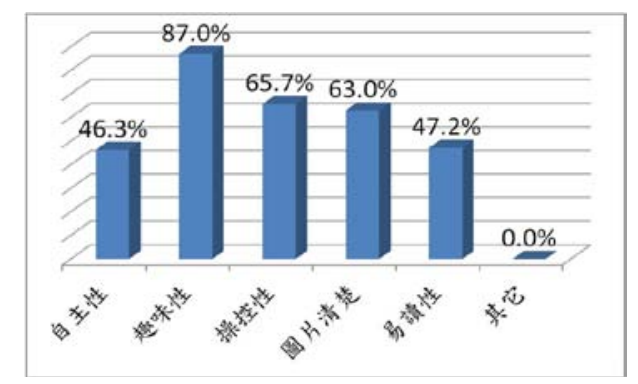

(e)

Figure 10.

(a) Q1. Do you like using DGBI to learn about insect? (b) Q1. Do you like using DGBI to learn about insect? (c) Q3. Which learning activity is your favorite? (d) Q4 what's the advantage of DGBI? (e) Q4 what's the advantage of DGBI? 
- $52.0 \%$ of students think it is fun and interesting: "The insect game is fun. I think is fun to learn in games.” (LS-S809、LS-S827,LS-S909,20120508).

- $30.4 \%$ of students think that they help to understand the conception of insect more effective: "We can operate by ourselves and can understand the morphological of the insect. This let me know the mouthparts and see the insect clearly. " (LS-S104 、 LS-S821, LS-S902, LS-S201, 20120508).

Figure 10b shows students in preference to which teaching unit in DGBI teaching materials, including Bugs Adventure, Legs and Wings and Mouthparts and feeding habits. There are 91.0\% of students like the unit "Mouthparts and feeding habits." In the interview, 50.5\% of students think "Mouthparts and feeding habits" is the interesting game in DGBI, it added plentiful educational content, and makes this unit the most popular one. In the interview, student said: "If we can play insect games, then we can learn insect when we were playing, and know what king of mouthparts they got” (LS-S927, LS-S104, LS-S826, 20120508). 32.3\% of students think Insect Breeder unit in the insect amusement in "Mouthparts and feeding habits" has design self-challenge checkpoints, can compete with their friends, has the ability to manipulate more, and the speed becomes faster and faster which makes it challenging(LS-S922, LS-S820, LS-S117, LS-S908, 20120507).

From Figure 10c, we can found that students preference of "Dole's insect mission", "Conception map" and "Insect amusement”. $85.2 \%$ of student like the Insect amusement; the reason is same as Figure 10d.

We can know students idea of DGBI from: $87.0 \%$ of student think DGBI is fun to play, $65.7 \%$ of students thinks is easy to control, $63.0 \%$ of students think that picture in DGBI can let them discern the insect. Figure 10e shows that $48.7 \%$ thinks the designing of DGBI is excellent; $23.5 \%$ of students thinks the teaching content is too difficult to learn, $22.6 \%$ of students thinks that the picture is not clearly enough, another $5.2 \%$ of students thinks that we can increase more picture and entomology in DGBI.

\section{Conclusion}

\section{Follow ADDIE Pattern can Develop Good Quality of DGBI Teaching Materials}

The DGBI teaching materials develop by following the five step of ADDIE pattern. First, we analysis student's alternative conception when they identify insects and the appearance structure of insect. Second, we use conflict concepts tactics, computer simulation tactics and mapping concept tactics as foundation to design the whole structure of the DGBI. Then, we collected element that we needed and the use Adobe Flash CS4 to animate DGBI. After testing DGBI, we adopted the expert's suggestion and three functions: First, we added Hymenoptera insect to increase the richness and completeness of DGBI. Second, we added the function of showing the correct answer and learning key points to let the lower packet of pupils can finish the learning in DGBI. The last but not least, we added the function of strengthen the audio and timing to give the students immediately learning feedback. In the evaluation phase, the DGBI obtain the AAA certification, which display DGBI is an excellent digital teaching materials.

\section{DGBI Teaching Materials can Let Students to Learn Insect Concept Step by Step}

DGBI teaching materials have good teaching content, teaching goals, learning direction and teaching media, which can help students learning insect concept orderly and gradual. In DGBI, we also provide diverse applications examples to students. First, we selected the text words and the picture that we use in DGBI to fit the awareness level of the learner; secondly, DGBI has pictures that can turn 360 degrees, zoom up partial features and break through the limit of paper page.

In the learning direction part, DGBI guide the students by a narrative context, leading the students from their original concept of cognitive, and let them choice their own learning path. The answer shown function can provide the underperformed children some help before game over.

\section{DGBI Teaching Materials can Improve Students Interested in Learning Insect}

Compare to "Bugs Adventure”, "Legs and Wings", and "Mouthparts and feeding habits" three teaching activities, there's $91.0 \%$ of students likes the "Mouthparts and feeding habits" activities. Compare three teaching activities "Dole's insect mission", "Conception map" and "Insect amusement”, $85.2 \%$ of students likes the "Insect amusement" activity. Student thinks the "Mouthparts and feeding habits" unit has rich learning content and exciting game, which has self-challenge design (the speed with become faster and faster) and can compare their score with others, and make this unit their favorite one.

\section{DGBI Teaching Materials can Help Students to Build the Right Insect Concepts}

According to the pretest and posttest scores in t-test in the "Insect cognitive conception test", we found that after using DGBI teaching materials, students can have better insect concepts, especially in insects cognitive and insect identification, position of the legs and wings, and mouthparts and feeding habits. Among all the conceptions, the position of the legs and wings enhance the most; especially the lower packet of pupils has increase the most in their learning.

\section{Expansion Form Teachers Brings Out the Best DGBI Teaching Effect}

DGBI teaching materials emphasized students can learn independently by themselves, but will they have another alternative conception needs more research to test and verify. If teachers can explain some concept when using DGBI, it can bring out better effects. From the experimental teaching result, we suggest when teaching insect curriculum, teachers can use DGBI teaching materials as a motivate activity. Then, teachers can ask students to observe the entity insect and write down their discovery. In the end, teacher can let the students to use DGBI teaching materials and discuss and clarify their conceptions together, this cam exert DGBI teaching material's maximize learning benefits in insect teaching.

\section{Recommendations for Digital Teaching Researchers}

For some of the students, DGBI teaching material is a little bit hard to learn. Therefore, we recommend digitals designers and researchers can study what kind of students think DGBI is 
hard to use and gets difficult in learning. When use DGBI, designers and researchers can also study if students reading ability, prior scientific concepts or other reasons will restrict them using DGBI.

\section{Acknowledgements}

We appreciated to those who made the completion of this study possible, including: funding supported from the National Science Council Taiwan, R.O.C. (NSC101-2511-S-152-010MY2), teachers who takes questionnaires, teachers who join focus grouping interview and senior teachers who assist the entire researcher. Last but not less, the supports from our research team.

\section{REFERENCES}

Bell, B., \& Barker, M. (1982). Towards a scientific concept of 'animal'. Journal of Biological Education, 16, 197-200.

Chen, J. Z. (2004). A study of the insect diversity and conservation. In Forestry Bureau, COA (Eds.) Proceedings of the Symposium on Insect Conservation and Biodiversity, (pp110-126). Taipei, Taiwan.

Chen, S. T. (2003). A Study of elementary school students' cognition and alternative conception on aquatic insects in Taoyuan. A Master's thesis of Municipal Taipei University of Education

Chuang, C. Y. \& Su, Y. J. (1999). A study of the perception selection and conception of animal classification in primary school children. Chinese Journal of Science Education,7(2), 135-156.

Huang, W. C. (2003). A study of elementary school students' conceptions and misconceptions about insects by two-tier diagnostic instrument. A Master's thesis of National Taichung University of Education.

Jeng, S. L. (2012). Develop the digital game based on the conception of inscets to incrcase the conceptions of elementary school students. A Master's thesis of National Taipei University of Education.

Lu, C. C. \& Chen, Y. Y. (2008). Integrating digital storybooks into teaching to promote children's cognitive concepts of animal growth. Journal of Educational Practice and Research, 21(2), 33-62.

Lu, C. C. \& Chen, P. J.(2011, April, 23). The development of insect conception comprehension tests in elementary teachers. Paper presented at Conference on Science Education and Science, Taipei, Taiwan.

Lu, C. C., Chen, Y. Y., \& Chen, C. W. (2011). A correlative study of CD-ROM storybooks in classrooms and school children's formation of descriptive concepts. International Journal of Science and Mathematics Education, 9(1), 47-67.

Marriott. S (2002). Red in tooth and claw? Images of nature in modern picture books. Children's Literature in Education, 33(3), 175-183.

Molenda, M. (2003). In search of the elusive ADDIE model. Performance improvement 42 (5), 34-37.

Shepardson, D. P. (2002). Bugs, butterflies, and spiders: Children's understandings about insects. Internation Journal of Science Education, 24(6), 627-643.

Squire, K. (2003). Video games in education. International Journal of Intelligent Simulations and Gaming, 2(1), 49-62.

Sung, Y. T., Chang, K. E., Lin, H. L., Lee, Y. F., \& Chen, M. P. (2009). Establishing certification standard for e-learning courseware quality and analyzing its reliabilities. Journal of e-Business, 11(4), 823-846.

Trowbridge, J. E., \& Mintzes, J. J. (1988). Alternative conceptions in animal classification: A cross-age study. Journal of Research in Science Teaching, 25, 547-571.

Tsai, H. T. (2008). On the relationships bewteen concept map strategies and web search capability: An experiment on sixth grade students. A Master's thesis of National University of Tainan.

Zhuang, S. J. (2002). Action research of elementary school students' learning camp insects. A Master's thesis of National Taipei University of Education. 